UDC 347.1

LBC 67.404

\title{
AXIOLOGICAL AND NORMATIVE FUNCTION OF THE LEGAL CULTURE AND ITS ROLE IN SHAPING THE FAITHFUL IMPLEMENTATION OF CIVIL RIGHTS AND DUTIES
}

\author{
Evgeny Yu. Malikov \\ Volgograd Regional Branch of the All-Russian Public Organization "The Association of Lawyers of Russia", \\ Volgograd, Russian Federation
}

Introduction: the formation of the legal culture of citizens is the most important condition of stability and public order in the society and a necessary element of a law-bound state. The most important function of the legal culture is an axiological and normative function which allows to assess the status of law, order, legal relations, and the mechanism of the statutory regulation and so on. The assessment is subjected to both any legal situation and the legal system as a whole. The legal culture is directly linked to the legal consciousness and legal education. In turn, all of these factors influence the process of the fair exercise of civil rights and duties. The objective is to analyze the effect of the legal education, legal consciousness and legal culture in the formation of the faithful implementation of civil rights and duties. The scientific methods used are the following: (logical, systematic, functional ones); private law methods (formal and legal, comparative legal ones). Results: there has been analyzed the position of the scientists on the formation of the legal culture, legal education, the formation of a high legal consciousness. There have been set the stages of formation, forms, methods and techniques. There has been investigated the relationship of these factors. Conclusions: it is proved that the faithful implementation of civil rights and duties depends on the level of the legal culture, both an individual and social one. There have been determined the factors influencing the formation of the legal culture. There has been set the dependency of the legal culture level of various aspects, including the legal education, and the level of legal consciousness. It is proved that in the category of legal consciousness one should provide the intellectual and emotional components. There are four basic forms of legal education. It is proved that the individual's legal consciousness is formed and developed under the influence of a variety of the objective and subjective factors. There has been set a list of them.

Keywords: legal culture, legal education, legal consciousness, implementation of civil rights, discharge of duties.

УДК 347.1

ББК 67.404

\section{ЦЕННОСТНО-НОРМАТИВНАЯ ФУНКЦИЯ ПРАВОВОЙ КУЛЬТУРЫ И ЕЕ РОЛЬ В ФОРМИРОВАНИИ ДОБРОСОВЕСТНОГО ОСУЩЕСТВЛЕНИЯ СУБЪЕКТИВНЫХ ГРАЖДАНСКИХ ПРАВ И ИСПОЛНЕНИИ ОБЯЗАННОСТЕЙ}

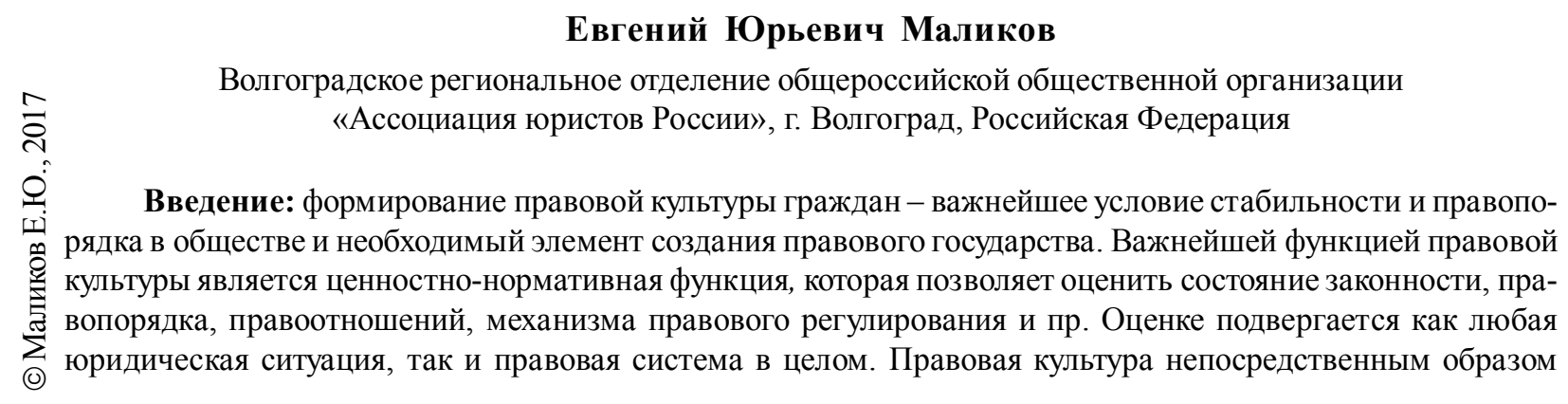


связана с правосознанием и правовым воспитанием. В свою очередь все эти факторы оказывают влияние на процесс добросовестного осуществления гражданских прав и исполнения обязанностей. Цель исследования: проанализировать влияние правового воспитания, правосознания и правовой культуры на формирование добросовестного осуществления субъективных гражданских прав и исполнение обязанностей. При проведении исследования использовались общенаучные методы (логический, системный, функциональный); частноправовые методы (формально-юридический, сравнительно-правовой). Результаты: анализируются позиции ученых по вопросам формирования правовой культуры, правового воспитания, формирования высокого правосознания. Устанавливаются этапы формирования, формы, методы и способы. Исследуется взаимосвязь указанных факторов. Выводы: обосновывается, что добросовестное осуществление гражданских прав и исполнение обязанностей зависят от уровня правовой культуры, как индивидуальной, так и общественной. Выделяются факторы, влияющие на формирование правовой культуры. Устанавливается зависимость уровня правовой культуры от различных аспектов, в том числе правового воспитания и уровня правосознания. Обосновывается, что в категории правосознания следует выделять интеллектуальную и эмоциональную составляющие. Выделяются четыре основные формы правового воспитания. Доказывается, что правосознание индивида формируется и развивается под воздействием различных объективных и субъективных факторов, устанавливается их перечень.

Ключевые слова: правовая культура, правовое воспитание, правосознание, осуществление субъективных прав, исполнение обязанностей.

\section{Введение}

Развитие правового государства и формирование гражданского общества в России невозможны без высокой правовой культуры, отсутствие которой не позволит в полной мере реализовать такие фундаментальные ценности, как верховенство закона, неотчуждаемость прав и свобод человека и гражданина, обеспечение надежной защиты интересов всех членов общества.

Сегодня в условиях бурного изменения законодательства возрастает значимость исследования теоретических и практических аспектов формирования правовой культуры [4, с. 177].

Правовая культура - важнейший элемент правовой системы общества. Она охватывает все правовые ценности. Чем выше уровень правовой культуры граждан, тем эффективнее функционируют как правовая, так и политическая и экономическая системы общества. От уровня правовой культуры зависят гражданская позиция и активность граждан, их непосредственное участие в управлении государственными, общественными делами, уровень осуществления субъективных гражданских прав и исполнения обязанностей.

При этом решающую роль для формирования правовой культуры играет не принуждение и навязывание правовых знаний и ценностей, а воспитание осознания того, что законы необходимо знать и не нарушать. Пра- вовая культура способствует утверждению основополагающих правовых принципов, формированию правопорядка, правомерного поведения граждан, чувства правовой ответственности членов общества.

\section{Виды и функции правовой культуры}

Правовая культура - часть культуры общества или личности. Она непосредственно связана с политической, нравственной и другими видами культуры.

Ученые рассматривают правовую культуру как сферу человеческой деятельности, представляющей собой совокупность норм, ценностей, юридических институтов, процессов и форм $[6$, с. $213 ; 9$, с. 234], либо систему правовых знаний, навыков, действий, проявляемых в сфере тех или иных правоотношений, уважении к действующему законодательству, его неукоснительном соблюдении [1, c. $20 ; 10$, c. 134$]$.

«Норма права, как и право в целом, определяет границы возможных и должных поступков в тех или иных отношениях и тем самым обеспечивает меру свободы индивида. Таким образом, норма права является критерием правомерности поведения субъектов» $[3$, c. 92]. Правовая культура отражает не только знание индивидом правовых норм, но и понимание их, отношение к ним, способность и готовность применять эти нормы в практической жизни. 
Таким образом, правовая культура выражается в правовых установках и ценностных ориентациях индивида и связана не только с его уровнем грамотности, но и его воспитанием, отношением к праву, дисциплине, уважением закона, прав других субъектов.

Важнейшей функцией правовой культуры является ценностно-нормативная функция, которая, на наш взгляд, должна характеризоваться двумя аспектами. С одной стороны, она связана с созданием и закреплением в нормах права правовых и нравственных гарантий таких ценностей, как справедливость, добросовестность, свобода. С другой стороны, она позволяет оценить само право с позиции нравственных ценностей, всей совокупности законодательства, конкретных правовых норм, поведения граждан, деятельности правоохранительных органов.

Ценностно-нормативная функция позволяет оценить состояние законности, правопорядка, правоотношений, механизма правового регулирования и пр. Оценке подвергается как любая юридическая ситуация, так и правовая система в целом.

В науке выделяют следующие виды правовой культуры: правовую культуру общества, правовую культуру личности и правовую культуру различных групп населения (это может быть профессиональная культура, культура отдельных социальных слоев и др.) [5; 7, с. 33].

В контексте настоящего исследования нас в первую очередь интересует правовая культура личности, ведь именно она является основой для осуществления субъективных гражданских прав и исполнения обязанностей. Именно ее уровень позволяет говорить о надлежащем, разумном и добросовестном правоосуществлении.

При этом необходимо помнить, что «поскольку любой человек всегда существует в конкретной среде: семьи, трудового коллектива, населенного пункта, государства - общественное для него является естественной и по сути единственной средой его бытия... Но все общественное имеет в своей основе политику и предопределяется политической реальностью. Политическое формирует все мировоззренческие, культурные, духовные, психологические, социальные и хозяйственные установки, на которых основывается любой человеческий коллектив» [2, с. 99].

Правовую культуру личности следует характеризовать пятью аспектами. Первый это, конечно, знание основных положений действующего законодательства и понимание их сути и назначения. Второй - соблюдение, исполнение или грамотное использование законов. Третий, крайне важный, характеризует как уровень правосознания, так и уровень правовой культуры личности: положительное отношение к законам, убеждение в необходимости их существования. Четвертый - осознание своих прав и обязанностей, ответственности, а также наличия таких же прав, обязанностей и ответственности у других граждан, умение находить баланс между осуществлением своих прав и ненарушением прав других субъектов. Пятый - активная деятельность, направленная на пресечение коррупционного поведения и других правонарушений, содействие поддержанию правопорядка, преодоление правового нигилизма в обществе.

Таким образом, правовая культура включает в себя не только высокоразвитое правосознание, основанное на положительной оценке права и его применения, но и правомерную активную правовую деятельность, добросовестное осуществление гражданских прав и исполнение обязанностей, непричинение вреда другим лицам в результате осуществления субъективных прав.

От того, насколько у отдельной личности сформирована правовая культура, зависит в конечном итоге уровень правовой культуры всего общества. Необходимо выделить шесть факторов, влияющих на формированиеправовой культуры в обществе. Во-первых, это высокий уровень правосознания большинства граждан. Вовторых, наличие развитой системы законодательства, в том числе относительно прав и свобод граждан, их гарантий. В-третьих, эффективная работа всех ветвей власти, что в равной степени относится к законодательной, судебной и исполнительной власти. В-четвертых, сюда следует отнести неуклонное соблюдение, исполнение и использование норм права и основных принципов. B-пятых, это состояние законности и правопорядка в обществе. В-шестых, активная деятельность государства и большинства граждан, направленная на пресечение правонарушений, содействие 
поддержанию правопорядка, преодолениеправового нигилизма в обществе.

Мерами, направленными на формирование высокой правовой культуры, выступают: наличие правовой идеологии; правовое воспитание; формирование и развитие гражданского правосознания; повышение уровня доверия граждан к деятельности государства, обеспечение тесного взаимодействия государства с институтами гражданского общества; содействие предупреждению и разрешению социальных конфликтов; создание стройной и непротиворечивой системы законодательства; реализация гражданских инициатив, направленных на защиту прав и свобод человека и гражданина; обеспечение прозрачности и открытости деятельности органов государственной власти, органов местного самоуправления, иных органов и организаций, осуществляющих публичные полномочия; формирование в обществе нетерпимости к коррупционному поведению; повышение эффективности деятельности органов государственной власти, органов местного самоуправления, иных органов и организаций, осуществляющих публичные полномочия, и многие другие.

\section{Формы правового воспитания детей и молодежи}

В свете данного научного анализа нас в первую очередь интересуют правовое воспитание и формирование развитого правосознания, которые являются основополагающими факторами, влияющими на процесс осуществления субъективных гражданских прав и исполнения обязанностей.

Важно уже в раннем возрасте заложить основы правовых знаний, сформировав четкое представление не только о правах, но и об обязанностях, ответственности, воспитывать в духе неукоснительного соблюдения положений закона. В процессе правового воспитания важно сформировать у каждого гражданина верное понимание права и его роли в жизни общества, его ценность и необходимость.

Отсутствие правовой грамотности может оказать серьезное негативное влияние на общественное правосознание и правопорядок, лишает возможности эффективно участвовать в принятии важных государственных решений.
Следует выделять четыре основные формы правового воспитания:

Первая - правовая пропаганда. Сюда относится выработка идеологии (создание идеалов, поддерживаемых большинством населения и позволяющих сохранять в обществе высокий уровень толерантности, сплоченности, уважения к праву, законопослушности); популяризация идеологии (проведение научных мероприятий: конференций, круглых столов, лекций, консультаций и пр.; издание просветительских книг и брошюр; выступления, аналитические обзоры в средствах массовой информации; ответы на вопросы слушателей и читателей и др.). Важное значение здесь имеет просветительская и консультационная деятельность различных общественных организаций, оказывающих, в том числе, и бесплатную юридическую помощь, деятельность уполномоченных по правам человека (омбудсменов), правозащитных организаций.

Вторая - правовое обучение (формирование знаний, навыков и умений в образовательных организациях разного уровня (школах, училищах, колледжах, высших учебных заведениях, организациях дополнительного образования и пр.). Важным фактором в правовом воспитании выступает система юридического образования, обеспечивающая приобретение необходимых знаний о феномене права, его принципах, правотворческой и правоприменительной деятельности; развитие навыков грамотного применения норм права на практике, способствующее формированию чувства уважения к праву, активной гражданской позиции.

Любые ошибки в правотворческой, правоприменительной деятельности негативно отражаются в общественном сознании, формируя, в том числе, и отрицательное отношение к праву, его значению. Неквалифицированное, неправильное толкование тех или иных правовых норм порождает неверные правовые решения, которые дискредитируют деятельность правоприменительных органов, что выражается в скептическом отношении к ним.

Высокий уровень юридического образования стимулирует правомерное поведение граждан, формирует позитивное общественное мнение по вопросам права, минимизирует возможность неправомерного поведения. 
Третья - юридическая практика, повседневный опыт (участие в судебных процессах в качестве истца, ответчика, потерпевшего, присяжного и др.; заключение разного рода гражданско-правовых сделок, пользование услугами адвоката и др.).

Четвертая - самообразование (самостоятельное изучение законодательства, научной литературы, осмысление правовых явлений, окружающей правовой действительности).

Главная цель правового воспитания - формирование у гражданина высокого уровня правосознания. Речь идет о воспитании человека, знающего и уважающего закон и порядок, противодействующего правонарушениям, правовому нигилизму, коррупционному поведению и прочим негативным явлениям в обществе.

Правосознание- одна из форм общественного сознания наряду с политическим, научным, философским и прочими. Правосознание отражает то, как человек понимает право и как он к нему относится. Поэтому, полагаем, в правосознании следует выделять интеллектуальную и эмоциональную составляющие.

Интеллектуальная составляющая показывает знание и понимание правовых норм, принципов права, законности, правопорядка, правотворчества и пр. Эмоциональная составляющая отражает отношение субъекта к тем или иным нормам права и другим правовым явлениям с точки зрения их справедливости или несправедливости, совершенства или несовершенства, достоинств или недостатков. Эмоциональная оценка может быть разной не только у различных субъектов, но и у одного человека. Это может быть одобрительная оценка одних правовых норм и отрицательная реакция на другие.

Правосознание формируется у каждого человека. И у каждого человека оно разное. Неразвитое или деформированное правосознание является почвой для правонарушений, антисоциального поведения. Государство заинтересовано в том, чтобы его граждане имели развитое правосознание, в основе которого лежит знание и понимание законов, общее положительное отношение к праву и его применению.

Правосознание формируется в детстве, при этом основную роль здесь играют родители и педагоги. От уровня правосознания последних зависит формирование индивиду- ального правосознания ребенка. Правосознание индивида формируется и развивается под воздействием различных объективных и субъективных факторов. Среди объективных факторов значение имеют сложившиеся в обществе экономические отношения, политическая ситуация, уровень социального развития общества, образования и другие обстоятельства. В качестве субъективных факторов, воздействующих на индивидуальное правосознание, выступает уровень общего интеллектуального развития личности, ее психологический склад.

Правовое сознание тесно связано с нравственным сознанием. В праве заложены многие моральные нормы: справедливости, добросовестности, незлоупотребления и пр. Поэтому в правосознании переплетаются как юридические, так и этические нормы.

Структуру правосознания составляют два элемента: идеология и психология. Идеология - это система правовых идей, взглядов, воззрений. Идеология - это фундамент, на котором формируется правосознание. Чем человек грамотней в области права, чем больше он знает, тем сильнее его идеология. Психологическая составляющая правосознания это отношение индивида к праву, его чувства и переживания, связанные с восприятием права и его применением им самим, другими субъектами, в том числе государством, правоохранительными органами.

При этом психологическое отношение может быть не только индивидуальным, но и массовым. Это может быть возмущение каким-либо тяжким преступлением, тем, что преступник не пойман и не привлечен к ответственности, или чувство удовлетворения тем, что справедливость восторжествовала и законность восстановлена. Общественное правосознание играет определенную роль при совершенствовании действующего законодательства, например, при введении уголовной ответственности за те или иные деяния; установлении пенсионного возраста (как известно, отрицательное отношение населения к его увеличению уже несколько лет препятствует принятию закона, направленного на увеличение пенсионного возраста).

Развитие правосознания порождает добросовестное осуществление прав и исполне- 
ние обязанностей. Однако развитое правосознание формируется не у каждого индивида. Под воздействием различных факторов возможно искажение, «разрушение» позитивных идей, убеждений, установок и т. п.

В научной литературе выделяют виды деформированного правосознания: правовой инфантилизм (недостаточность правовых знаний при уверенности в хорошей юридической подготовке); правовой дилетантизм (небрежное отношение к юридическим ценностям); правовой нигилизм (отрицание социальной ценности права; осознанное игнорирование требований закона) [5, с. 567].

Государству очень важно бороться со всеми проявлениями деформированного правосознания. Для этого необходимо повышение общей и правовой культуры граждан, их правового и нравственного сознания; совершенствование законодательства; профилактика правонарушений; упрочение законности и правопорядка; уважение и защита прав личности; правовое просвещение и воспитание; подготовка высококвалифицированных юридических кадров; создание правовой идеологии и активная ее пропаганда и др.

\section{Выводы}

Добросовестное осуществление гражданских прав и исполнение обязанностей зависят от уровня правовой культуры. Она отражает знание субъектом правовых норм, понимание их, отношение к ним, способность и готовность применять эти нормы в практической жизни; выражается в правовых установках и ценностных ориентациях индивида и связана не только с его уровнем грамотности, но и его воспитанием, отношением к праву, дисциплине, уважением закона, прав других субъектов.

Важнейшей функцией правовой культуры является ценностно-нормативная функция, которая, с одной стороны, фиксирует в праве нравственные ценности, такие как справедливость, добросовестность, разумность, свобода. С другой стороны - внешней - позволяет оценить само право с позиции нравственных ценностей.

Устанавливая зависимость правовой культуры от различных факторов, следует считать, что основными являются: уровень правосознания, наличие развитой системы законодательства, эффективная работа всех ветвей власти в области правоосуществления, добросовестное осуществление гражданских прав и исполнение обязанностей, превенция правонарушений.

Считая важнейшим элементом формирования правовой культуры правовое воспитание, надлежит выделить четыре основные формы правового воспитания, которые необходимо реализовывать в совокупности для достижения положительного эффекта.

В научной категории правосознания следует выделять интеллектуальную и эмоциональную составляющие. Интеллектуальная показывает знание и понимание правовых норм, а эмоциональная отражает отношение субъекта к тем или иным нормам права и другим правовым явлениям. Правосознание индивида формируется и развивается под воздействием объективных и субъективных факторов. К основным объективным факторам, влияющим на осуществление субъективных гражданских прав и исполнение обязанностей, следует относить сложившиеся в обществе экономические отношения, политическую ситуацию, уровень социального развития общества, образования. В качестве субъективных факторов выступает уровень общего интеллектуального развития личности, ее психологический склад.

\section{СПИСОК ЛИТЕРАТУРЫ}

1. Авдеев, В. А. Правовое воздействие и правовая политика: вопросы институционализации и инструментальной сущности / В. А. Авдеев, О. А. Авдеева // Юридический мир. - 2015. - № 11. C. 19-23.

2. Грачев, Н. И. Политика и экономика в онтологии современного государства / Н. И. Грачев // Вестник Волгоградского государственного университета. Серия 5, Юриспруденция. - 2016. № 2 (31). - C. 93-100.

3. Дерюгина, Т. В. Пределы осуществления прав собственника на жилое помещение: коллизионные аспекты правового регулирования / Т. В. Дерюгина // Вестник Волгоградского государственного университета. Серия 5, Юриспруденция. -2015 . № 3 (28). - C. 92-96.

4. Епифанов, А. Е. Рец. на кн.: Павленко, Е. М. Образование в области прав человека как основа 
формирования правовой культуры и культуры прав человека в Российской Федерации [Текст] : монография / Е. М. Павленко. - М. : Права человека, 2016. - 216 с. / А. Е. Епифанов // Вестник Волгоградского государственного университета. Серия 5 , Юриспруденция. - 2016. - № 2 (31). - С. 177-179.

5. Ильин, И. А. О сущности правосознания / И. А. Ильин // Собр. соч. В 10 т. Т. 4 / И. А. Ильин. М. : Русская книга, 1994. - 654 с.

6. Малько, А. В. Цели и средства в праве и правовой политике / А. В. Малько, К. В. Шундиков. - Саратов : [Б. и.], 2003. - 294 с.

7. Матузов, Н. И. Общая концепция и основные приоритеты российской правовой политики / Н. И. Матузов // Правовая политика и правовая жизнь. -2000 . - № 8. - С. 33-46.

8. Мелехин, А. В. Теория государства и права / А. В. Мелехин. -2-е изд., перераб. и доп. - М., 2009. 545 с. - Подгот. для системы «КонсультантПлюс».

9. Теория государства и права / под ред. В. К. Бабаева. - 3-е изд., перераб. и доп. - М. : Юрайт, 2013. $-715 \mathrm{c}$.

10. Теория государства и права / А. И. Абрамова, С. А. Боголюбов, А. В. Мицкевич [и др.]. М. : Городец, 2003. - 544 с.

\section{REFERENCES}

1. Avdeev V.A., Avdeeva O.A. Pravovoe vozdeystvie i pravovaya politika: voprosy institutsionalizatsii i instrumentalnoy sushchnosti [Legal Effects and Legal Policy: Issues of Institutionalization and the Instrumental Nature]. Yuridicheskiy mir, 2015, no. 11, pp. 19-23.

2. Grachev N.I. Politika i ekonomika v ontologii sovremennogo gosudarstva [Politics and Economics in the Ontology of the Modern State]. Vestnik Volgogradskogo gosudarstvennogo universiteta. Seriya 5, Yurisprudentsiya [Science Journal of Volgograd State University. Jurisprudence], 2016, no. 2(31), pp. 93-100.
3. Deryugina T.V. Predely osushchestvleniya prav sobstvennika na zhiloe pomeshchenie: kollizionnye aspekty pravovogo regulirovaniya [Limits of the Rights of the Owner on the Premises: Collision Aspects of Legal Regulation]. Vestnik Volgogradskogo gosudarstvennogo universiteta. Seriya 5, Yurisprudentsiya [Science Journal of Volgograd State University. Jurisprudence], 2015, no. 3 (28), pp. 92-96.

4. Epifanov A.E. Rets. na kn.: Pavlenko, E. M. Obrazovanie v oblasti prav cheloveka kak osnova formirovaniya pravovoy kultury i kultury prav cheloveka v Rossiyskoy Federatsii [Tekst] : monografiya / E. M. Pavlenko. -M. : Prava cheloveka, 2016. -216 p. [Book Review: Pavlenko E.M. Education in the Field of Human Rights as the Basis of Formation of Legal Culture and Human Rights Culture in the Russian Federation [Text]: Monograph. Moscow, Prava cheloveka Publ., 2016. 216 p.]. Vestnik Volgogradskogo gosudarstvennogo universiteta. Seriya 5, Yurisprudentsiya [Science Journal of Volgograd State University. Jurisprudence], 2016, no. 2 (31), pp. 177-179.

5. Ilyin I.A. O sushchnosti pravosoznaniya [On the Essence of Legal Consciousness]. Sobr. soch. $V 10$ t. T. 4 [Collected Works. In 10 vols. Vol. 4]. Moscow, Russkaya kniga Publ., 1994. 654 p.

6. Malko A.V., Shundikov K.V. Tseli i sredstva v prave i pravovoy politike [Goals and Means in Law and Legal Policy]. Saratov, 2003. 213 p.

7. Matuzov N.I. Obshchaya kontseptsiya i osnovnye prioritety rossiyskoy pravovoy politiki [Overall Concept and the Main Priorities of the Russian Legal Policy]. Pravovaya politika $i$ pravovaya zhizn, 2000, no. 8, pp. 33-46.

8. Melekhin A.V. Teoriya gosudarstva i prava [Theory of State and Law]. 2nd ed., rev. and add. Moscow, 2009. 545 p. Prepared of the System "KonsultantPlyus".

9. Babaev V.K., ed. Teoriya gosudarstva i prava [Theory of State and Law]. 3rd ed., rev. and add. Moscow, Yurayt Publ., 2013. 715 p.

10. AbramovaA.I., BogolyubovS.A., MitskevichA.V., et al. Teoriya gosudarstva $i$ prava [Theory of State and Law]. Moscow, Gorodets Publ., 2003. 544 p.

\section{Information About the Author}

Evgeny Yu. Malikov, Candidate of Juridical Sciences, Associate Professor, Chairman of the Volgograd Regional Branch of the All-Russian Public Organization "The Association of Lawyers of Russia”, Gribanova St., 12, 400011 Volgograd, Russian Federation, 999666777e@gmail.ru, znanie@vggi.ru.

\section{Информация об авторе}

Евгений Юрьевич Маликов, кандидат юридических наук, доцент, председатель Волгоградского регионального отделения общероссийской общественной организации «Ассоциация юристов России», ул. Грибанова, 12, 400011 г. Волгоград, Российская Федерация, 999666777e@gmail.com, znanie@vggi.ru. 